\title{
Tailoring chimeric ligands for studying and biasing ErbB receptor family interactions ${ }^{\star *}$
}

\author{
Dr. Andrew T. Krueger, \\ Departments of Biology and Chemistry, Massachusetts Institute of Technology, 77 \\ Massachusetts Ave., Cambridge MA (USA), Fax: (+) 16174522419 \\ Dr. Carsten Kroll, \\ Departments of Biology and Chemistry, Massachusetts Institute of Technology, 77 \\ Massachusetts Ave., Cambridge MA (USA), Fax: (+) 16174522419 \\ Edgar Sanchez, \\ Department of Biological Engineering, Massachusetts Institute of Technology, 77 Massachusetts \\ Ave., Cambridge MA (USA) \\ Prof. Linda G. Griffith, and \\ Department of Biological Engineering, Massachusetts Institute of Technology, 77 Massachusetts \\ Ave., Cambridge MA (USA) \\ Prof. Barbara Imperiali \\ Departments of Biology and Chemistry, Massachusetts Institute of Technology, 77 \\ Massachusetts Ave., Cambridge MA (USA), Fax: (+) 16174522419 \\ Barbara Imperiali: imper@mit.edu
}

\section{Abstract}

We describe the development and application of a versatile semisynthetic strategy, based on a combination of sortase-mediated coupling and tetrazine ligation chemistry, which can be exploited for the efficient incorporation of tunable functionality into chimeric recombinant proteins. To demonstrate the scope of the method, we present the assembly of a set of bivalent ligands, which integrate members of the epidermal growth factor (EGF) ligand family. Using a series of bivalent EGFs with variable intraligand spacing, we correlate the differences in structure with the ability to bias signaling in the ErbB receptor family in a cell motility assay. Biasing away from EGFRHER2 dimerization with a bivalent EGF was observed to reduce cell motility in an intraligand distance-dependent fashion, demonstrating the utility of the approach for the tailored assembly of recombinant chimeric protein for acutely perturbing receptor-mediated cell signaling pathways.

\footnotetext{
** We acknowledge Prof. David Liu, Harvard University (Sortase mutant plasmids), Sherlyn Jaimes (assistance with motility assay), the Integrated Cancer Biology Program at MIT (U54-CA112967), R01DE019523-13 (L.G.G.), CSBI Merck-MIT postdoctoral fellowship (A.T.K.), Swiss National Science Foundation Postdoctoral Fellowship (C.K), and MIT NIEHS Toxicology Training Grant (E.S.) 5-T32-ES007020

Correspondence to: Barbara Imperiali, imper@mit. edu.

Supporting information for this article is available on the WWW under http://www.angewandte.org.
} 


\section{Keywords}

protein semisynthesis; ErbB receptors; sortase ligation; bioorthogonal chemistry; bivalent ligands; cell signaling

The ErbB/HER/epidermal growth factor receptor (EGFR) family comprises four closely related receptor tyrosine kinases (RTK) known to regulate diverse organismal phenotypes including cell migration, proliferation, and differentiation. ${ }^{[1]}$ Evidence supports activation by receptor-specific protein ligand binding that drives and stabilizes receptor dimerization or oligomerization. One member, HER2, has no known ligands but exists in a conformation that is poised for heterodimerization and subsequent signal transduction. Mutation, dysregulation and/or overexpression of the EGFR family receptors and/or their ligands is prevalent in many epithelial cancers, and specific receptor dimers -particularly heterodimers with HER2 - may propagate malignant signals. ${ }^{[2]}$ Understanding the complex mechanisms and interplay of these signaling processes and receptor dynamics is crucial for being able to open up new paradigms for targeting the EGFR signaling pathway. As such, the development of novel and diverse sets of tools designed to systematically manipulate receptor activation via non-genetic means should advance our knowledge towards new therapeutic approaches.

One promising strategy involves the tethering of two EGF family ligands to create "bivalent ligands. ${ }^{[3]}$ " Preliminary studies with cell lines treated with bivalent ligands for EGFR family members exhibit phenotypic and signaling behaviors consistent with a biasing of receptor dimerization or oligomerization away from those involving HER2, compared to treatment with monovalent ligands (as illustrated in Figure 1). Early prototypes of these bivalent ligands were created by recombinantly expressing individual ligands (either neuregulin- $1 \beta$ (NRG) or epidermal growth factor (EGF)) fused to one partner of a coiled-coil monomer motif and joining the desired ligands non-covalently, (later a bivalent single-chain construct was expressed $)^{[4]}$ with a fixed amino acid linker spacing.

The bivalent ligand strategy has opened the door for progress in elucidating the complex systems biology of the EGF receptor family in cancer therapeutics, regenerative medicine as well as other physiological processes. ${ }^{[5]}$ Therefore, the ability to efficiently produce a variety of bivalent ligands with tailored functionality to interrogate the EGFR signaling network and address fundamental biophysical questions regarding receptor dynamics and trafficking could potentially provide guidance towards, and lead to new models for therapeutic intervention.

To this end we have designed and established a general semisynthetic strategy for advancing the scaffold of bivalent protein ligands as a practical and diversely functionalized tool by taking a chemical approach in linking (in theory any) two recombinant protein ligands with a synthetic linker. This strategy allows for distance tunability, facile label incorporation, a covalent linkage, and a single expression strategy capable of producing multiple bivalent tools with customized linkages tuned to experimental objectives. The approach (Figure 2) relies on efficient expression of two proteins modified with short Nor C-terminal amino acid sequences for sortase mediated ligation. ${ }^{[6]}$ The ligation modifies the protein terminus with 
separate chemically-synthesized peptidic components including either a norbornene or tetrazine moiety which undergo a metal-free bioorthogonal ligation ${ }^{[7]}$ to link the proteins of interest (e.g. growth factors) via their termini in a C-to-N fashion. We demonstrate the utility of this method to synthesize an array of bivalent ligands based on EGF and NRG.

Furthermore, the set of bivalent EGF tools is applied in a phenotypic single cell migration assay, providing a structure-function relationship of effective reduction of cell migration as a function of linker length.

Our strategy initially focused on optimization of recombinant growth factor expression using the 53-amino acid EGF ligand as a prototype. Ultimately, we could obtain efficient expression and purification of EGF in E. coli and "reagent quantities" ( $\sim 30-50 \mathrm{mg} / \mathrm{L})$ of EGF could consistently be generated (see SI for gene sequences and expression methods). ${ }^{[8]}$ Mutagenesis allowed incorporation of either N-terminal GGG- or C-terminal -LPRTGGG sortase recognition sequences and gave similar expression yields. Similar yields with neuregulin- $1 \beta$ were also obtained.

Peptidic linker components for incorporation of chemical diversity into the bivalent linkage were designed to systematically vary the linker length within the bivalent ligand to probe its effect on biasing receptor interactions. To this end we synthesized a set of norbornenemodified peptides 1-5 for $\mathrm{N}$-terminal ligand modification (see SI for synthetic details). The variation of linker length was achieved during peptide synthesis via commercially available Fmoc-protected $\mathrm{PEG}_{\mathrm{n}}$ amino acid building blocks, ultimately providing intraligand distances ranging from $50 \AA-180 \AA$. For C-terminal ligand modification, a 4-(6-methyl-1,2,4,5tetrazin-3-yl)benzylamine-functionalized, 5(6)-carboxyfluorescein-labeled triglycine peptide $\mathbf{6}$ was synthesized. The 6-methyl variant of the tetrazine was selected due to increased stability towards aqueous environments and peptide synthesis conditions. ${ }^{[7 \mathrm{~b}]}$

Using an evolved triple mutant of the sortase enzyme ${ }^{[10]}$ and expressed GGG-EGF and EGF-LPRTGGG constructs, EGFs were modified with either tetrazine-containing peptide $\mathbf{6}$, or peptides 1-5 to produce a set of modular monovalent EGFs containing bioorthogonal handles. Optimized conditions allowed for full conversion (as monitored by LC/MS) after 30 minutes up to milligram scales of protein using less than 3 equivalents of peptide. Purification involved a simple two-step process of filtering through NiNTA resin to remove the His $_{6}$-tagged sortase enzyme, followed by size exclusion chromatography. Neuregulin- $1 \beta$ was modified via sortase-mediated ligation with the same modular components. The tetrazine/norbornene-PEG $_{\mathrm{n}}$-modified EGF and NRG products were verified by LC/MS (Tables S1, S2, Figure S1) and showed biological activity comparable to wild type EGF/NRG as confirmed by downstream kinase activation of ERK 1/2 and AKT (Figure S2).

With the tetrazine and norbornene handle-modified monovalent pieces in hand, simple incubation of the appropriate components in aqueous buffer afforded bivalent ligands. The various semisynthetic bivalent EGF (EE) and NRG (NN) ligands were synthesized by combining the modified monovalent pieces in a 1.2:1 (tetrazine:norbornene piece) ratio $(\sim 100 \mathrm{uM})$ and incubating at room temperature for $24 \mathrm{~h}$, after which ligation progress appeared to plateau as observed by SDS-PAGE (Figure 3A). ${ }^{[11]}$ Purification via size exclusion chromatography yielded a set functionalized bivalent ligands with variable tether 
lengths with purities estimated (by LC/MS profiles) at greater than 95\% (Figure 3B, Figures S3, S4).

To validate the new chimeric constructs and demonstrate the utility of the strategy, we implemented the set of semisynthetic bivalent EGF ligands in single cell motility assays in hTERT mesenchymal stem cells (hTMSCs). Previous studies showed that a coiled-coil bivalent ligand induced EGFR clustering/oligomerization on the cell surface resulting in biasing of EGFR-mediated signaling in hTMSCs suggesting that a role in cell motility may also be biased upon bivalent ligand treatment. ${ }^{[11]}$ This particular cell line is known to express EGFR, HER2, and HER3 with no quantifiable HER4. It is hypothesized that an important signaling pathway in hTMSC migration occurs through the initiation of EGFRHER2 heterodimerization from binding of EGF to EGFR (HER2 has no associated ligand). ${ }^{[12]}$ As such, biasing EGFR away from interaction with HER2 toward EGFR homodimers should lead to a decrease in cell motility. Moreover, depending on the EE intraligand distance, this motility phenotype may be attenuated to varying degrees, providing a structure-function relationship in this context, which may reveal insight into signaling pathways and guide potential strategies for intervention.

Treatment of hTMSCs with various concentrations of either of the bivalent ligands (50 $\AA$ $180 \AA$ ) or their tether-modified monovalent counterparts resulted in diverse motility behaviors as quantified by tracking the paths of 50 individual cells for each condition (Figure S5-S7) and analysing these tracks to obtain quantifiable metrics of cell motility: total pathlength vs. net displacement from initial position (Figures 4A and S8A) and the random motility coefficient, which captures contributions from cell speed and persistence (Figure 4B, Figures S8B-S9). At $100 \mathrm{nM}$, a concentration expected to result in receptor saturation (unmodified EGF $\mathrm{K}_{\mathrm{D}} \sim 1 \mathrm{nM}$ ), bivalent ligands with intraligand spacing ranging from $90-180 \AA$ showed a marked decrease in cell motility relative to unmodified monovalent EGF or the monovalent tether-modified variants, with $90 \AA$ A-spaced bivalent exhibiting the largest reduction (Figure 4B). Interestingly, for the shorter EE ligands (50 A, $65 \AA$ ) at $100 \mathrm{nM}$ the stimulated migration phenotype was comparable to the monovalent counterparts and to unmodified EGF. Similar trends were observed at a ligand concentration comparable to $\mathrm{K}_{\mathrm{D}}(1 \mathrm{nM})$, where the $90 \AA$ spacing resulted the greatest inhibition of motility compared to monovalent counterpart or native EGF (Figure S6B). One observation of note is the PEG tether-modified EGF monovalent ligands stimulated motility parameters above the levels for native unmodified EGF.

Crystallographic information from a structure of two bound EGFs in a EGFR homodimer shows an estimated interligand distance of about 90-100 ̊ (C-to-N terminus, Figure 5). ${ }^{[13]}$ As such, our ligand set straddles the minimum required distance (linker distances estimated via published or modeling data for peptide and PEG motifs) ${ }^{[14]}$ for one bivalent ligand to sequester a homodimer. Previous bivalent ligands had an intraligand distance of $\sim 200 \AA$, and while capable of exhibiting a biasing effect, our study shows the benefit of screening a variety of distances to maximize a signal bias. The strongest migration reduction at $90 \AA$ does not seem too surprising considering the length of the PEG chain, allowing this bivalent to span the EGFR homodimer. This could factor into the relatively slight increase in cell migration with longer linker lengths, corresponding with the increase in entropy from less 
preorganization. ${ }^{[15]}$ The restoration of cell motility at linker lengths below $90 \AA$ may suggest the inability of the bivalent ligand to "wrap around" an EGFR homodimer and effectively bias away from an EGFR-HER2 heterodimer. However, it could also be possible to bias receptor interactions via concatenation (as illustrated in Figure 1), which would not necessarily require an intraligand distance that spans the homodimer active sites, but still may be sterically hindered from occurring. Our migration data suggests with the shorter EE ligands, that concatenation is not favored. Nevertheless, the ease with which these ligands can be produced will allow future biophysical and biochemical assays to understand EGFR dynamics and phenotypic effects. Nevertheless, the ease with which these ligands can be produced will allow future biophysical and biochemical assays to understand EGFR dynamics and phenotypic effects.

While the data support the concept that the bivalent ligands are biasing dimerization or oligomerization toward EGFR homodimers and away from EGFR-HER2 heterodimers (Figure S10), it is also possible that the ligands are perturbing the biophysical association of the juxtamembrane domain involved in receptor activation to cause differential signaling, in a manner similar to that reported for differences in TGFa and EGF. ${ }^{[16]}$ The variable stimulatory response of monovalent tether-modified EGF could similarly be altering EGFR biophysical states during activation. Overall, the observation that the tether-modified monovalent EGFs stimulate cell migration beyond that of wild type EGF is curious. It is possible the PEG tethers may sterically impede binding, and previous studies of loweraffinity, weaker binding EGF ligands having increased migration-promoting abilities are known. ${ }^{[17]}$ Quantitative binding data will be useful in confirming these observations.

Considering receptor dimerization or oligomerization is widely recognized among various cell surface receptor-mediated signaling pathways, the use of the described strategy for receptor ligands could also see utility in interrogating other signaling processes. ${ }^{[12 c, 18,19]}$ We are currently applying a similar set of bivalent neuregulins to downstream signaling, proliferation and phenotypic assays to elucidate its relevance in cancerous cells.

Although examples of semisynthetic bivalent ligand constructs in the size range defined in this study are limited, other approaches for synthesizing bivalent assemblies have included application of SPPS (smaller peptidic ligands), ${ }^{[20 a]}$ site-selective incorporation of cysteines/ aldehydes into antibodies/proteins for subsequent ligation and linking via CuACC or metalfree click reactions, ${ }^{[21,22]}$ as well as CuAAC chemistries on peptides ${ }^{[23]}$ or on proteins containing incorporated unnatural amino acids. ${ }^{[24]} \mathrm{We}$ chose to employ sortase mediated ligation due to robust conversion and small amino acid recognition sequences, allowing for efficient near-native protein expression - ultimately increasing the final semisynthetic bivalent ligand yields (3-6 mg/L vs. multi- $\mu \mathrm{g} / 10 \mathrm{~L}$ for the coiled coil and single chain constructs). Sortase mediated ligation has shown great use in linking proteins to proteins, peptides or other chemical entities. Recently, Ploegh and coworkers described utilizing sortase ligation and metal-free click chemistry to make $\mathrm{N}$-to-N fusions of ubiquitin vinylmethylester (UbVME) and C-to-C fusions of $\mathrm{VHH}$, a variable region of camelid antibodies. ${ }^{[25]}$ 
While in this study linkers included variable PEG spacers and a fluorescent label, one could envision incorporation of additional bioorthogonal handles for more diverse functionality, recognition or specific delivery, or further variation of the rigidity of the spacer utilizing polyproline motifs. ${ }^{[20]}$ Slight modulations in tether flexibility properties have been shown to play a remarkable role in stabilizing dimeric receptor interactions in other systems. ${ }^{[26]}$

In conclusion, we have described a robust, versatile method for incorporating tunable functionality into chimeric proteins and applied this method to bivalent growth factor ligands for studying and biasing EGFR signalling in hTMSCs using cell motility as a phenotypic readout. Although numerous studies of structure-function relationships for small molecules and their therapeutic targets are known and produce important insight, outside of mutagenesis studies, less examples exist with respect to larger protein ligands and their targets. Such studies, as well as methods for undertaking them will become invaluable moving forward our knowledge and perhaps establish new thought paradigms toward exploring the semisynthetic therapeutic space.

\section{Supplementary Material}

Refer to Web version on PubMed Central for supplementary material.

\section{References}

1. a) Olayioye MA, Neve RM, Lane AH, Hynes NE. EMBO J. 2000; 19:3159-3167. [PubMed: 10880430] b) Lemmon MA. Exp Cell Res. 2009; 315:638-648. [PubMed: 19038249] c) Linggi B, Carpenter G. Trends Cell Biol. 2006; 16:649-656. [PubMed: 17085050] d) Riese DJ 2nd, van Raaij TM, Plowman GD, Andrews GC, Stern DF. Mol Cell Biol. 1995; 15:5770-5776. [PubMed: 7565730]

2. a) Amin DN, Sergina N, Ahuja D, McMahon M, Blair JA, Wang D, Hann B, Koch KM, Shokat KM, Moasser MM. Sci Transl Med. 2010; 2:16ra17.b) Baselga J, Swain SM. Nat Rev Cancer. 2009; 9:463-475. [PubMed: 19536107] c) Ciardiello F, Tortora G. N Engl J Med. 2008; 358:11601174. [PubMed: 18337605]

3. Jay SM, Kurtagic E, Alvarez LM, de Picciotto S, Sanchez E, Hawkins JF, Prince RN, Guerrero Y, Treasure CL, Lee RT, Griffith LG. J Biol Chem. 2011; 286:27729-27740. [PubMed: 21622572]

4. Jay SM, Murthy AC, Hawkins JF, Wortzel JR, Steinhauser ML, Alvarez LM, Gannon J, MacRae CA, Griffith LG, Lee RT. Circulation. 2013; 128:152-161. [PubMed: 23757312]

5. Wiley HS, Shvartsman SY, Lauffenburger DA. Trends Cell Biol. 2003; 13:43-50. [PubMed: 12480339]

6. a) Proft T. Biotechnol Lett. 2010; 32:1-10. [PubMed: 19728105] b) Popp MWL, Antos JM, Ploegh HL. Curr Prot Prot Sci. 2009; 56:15.3.

7. a) Devaraj NK, Weissleder R, Hilderbrand SA. Bioconj Chem. 2008; 19:2297-2299.b) Karver MR, Weissleder R, Hilderbrand SA. Bioconj Chem. 2011; 22:2263-2270.

8. a) Marblestone JG, Edavettal SC, Lim Y, Lim P, Zuo X, Butt TR. Protein Sci. 2006; 15:182-189. [PubMed: 16322573] b) Butt TR, Edavettal SC, Hall JP, Mattern MR. Protein Expr Purif. 2005; 43:1-9. [PubMed: 16084395]

9. Lee JY, Yoon CS, Chung IY, Lee YS, Lee EK. Biotechnol Appl Biochem. 2000; 31:245-248. [PubMed: 10814596]

10. Chen I, Dorr BM, Liu DR. Proc Natl Acad Sci USA. 2011; 108:11399-11404. [PubMed: 21697512]

11. A minor, third band was observed on SDS-PAGE, attributed to an aggregate. Analysis revealed the aggregate is not dynamic, only appearing during the ligation reaction (Figure 3A). While the ligation with the slower reacting 6-methyl tetrazine variant required overnight to reach $\sim 70 \%$ 
completion, it proceeded equally well at $4{ }^{\circ} \mathrm{C}$. Lack of conversion may be due to partial decomposition of the tetrazine. Other ring-strained partners are being explored to increase reaction kinetics.

12. a) Kumar N, Zaman MH, Kim HD, Lauffenburger DA. Biophys J. 2006; 91:L32-L34. [PubMed: 16782798] b) Wu S, Wells A, Griffith LG, Lauffenburger DA. Biomaterials. 2011; 32:7524-7531. [PubMed: 21782235] c) Rodrigues M, Griffith LG, Wells A. Stem Cell Res Ther. 2010; 1:32-44. [PubMed: 20977782]

13. Lu C, Mi LZ, Grey MJ, Zhu J, Graef E, Yokoyama S, Springer TA. Mol Cell Biol. 2010; 30:54325443. [PubMed: 20837704]

14. a) Jeppesen C, Wong JY, Kuhl TL, Israelachvili JN, Mullah N, Zalipsky S, Marques CM. Science. 2001; 293:465-468. [PubMed: 11463908] b) Inagaki F, Ogura K, Kumeta H, Kobashigawa Y. J Biomol NMR. 2009; 43:145-150. [PubMed: 19140010] c) COSMOS 3D structure predictor. (http://cosmos.igb.uci.edu/)

15. Mammen M, Choi SK, Whitesides GM. Angew Chem Int Ed. 1998; 37:2754-2794.

16. Scheck RA, Lowder MA, Appelbaum JS, Schepartz A. ACS Chem Biol. 2012; 7:1367-1376. [PubMed: 22667988]

17. a) Wingens M, Jacobs-Oomen S, van der Woning SP, Stortelers C, van Zoelen EJJ. Biochemistry. 2006; 45:4703-4710. [PubMed: 16584205] b) Nandagopal K, Popp DM, Niyogi SK. J Cell Biochem. 2001; 83:326-341. [PubMed: 11573249] c) Reddy CC, Niyogi SK, Wells A, Wiley HS, Lauffenburger DA. Nat Biotechnol. 1996; 14:1696-1699. [PubMed: 9634854] d) Iyer AK, Tran KT, Griffith L, Wells A. J Cell Physiol. 2008; 214:504-512. [PubMed: 17708541]

18. Citri A, Yarden Y. Nat Rev Mol Cell Biol. 2006; 7:505-16. [PubMed: 16829981]

19. Engelman JA, Zejnullahu K, Mitsudomi T, Song Y, Hyland C, Park JO, Lindeman N, Gale CM, Zhao X, Christensen J, Kosaka T, Holmes AJ, Rogers AM, Cappuzzo F, Mok T, Lee C, Johnson BE, Cantley LC, Jänne PA. Science. 2007; 316:1039-1043. [PubMed: 17463250]

20. a) Tanaka T, Nomura W, Narumi T, Masuda A, Tamamura H. J Am Chem Soc. 2010; 132:15899_ 15901. [PubMed: 20973474] b) Nagel Y, Kuemin M, Wennemers H. Chimia. 2011; 65:264-267. [PubMed: 21678776]

21. Hudak JE, Barfield RM, de Hart GW, Grob P, Nogales E, Bertozzi CR, Rabuka D. Angew Chem Int Ed. 2012; 51:4161-4165.

22. Schellinger JG, Kudupudi A, Natarajan A, Du W, DeNardo SJ, Gervay-Hague J. Org Biomol Chem. 2012; 10:1521-1526. [PubMed: 22132412]

23. Sainlos M, Iskenderian-Epps WS, Olivier NB, Choquet D, Imperiali B. J Am Chem Soc. 2013; 135:4580-4583. [PubMed: 23480637]

24. Bundy BC, Swartz JR. Bioconj Chem. 2010; 21:255-263.

25. Witte MD, Cragnolini JJ, Dougan SK, Yoder NC, Popp MW, Ploegh HL. Proc Natl Acad Sci USA. 2012; 109:11993-11998. [PubMed: 22778432]

26. Martino MM, Mochizuki M, Rothenfluh DA, Rempel SA, Hubbell JA, Baker TH. Biomaterials. 2009; 30:1089-1097. [PubMed: 19027948] 

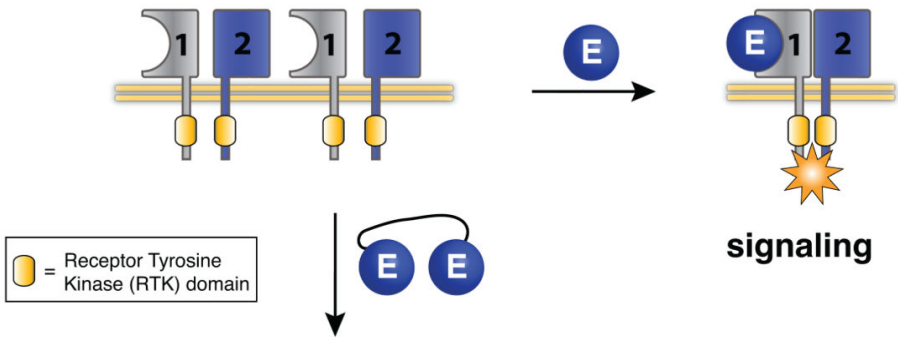

signaling

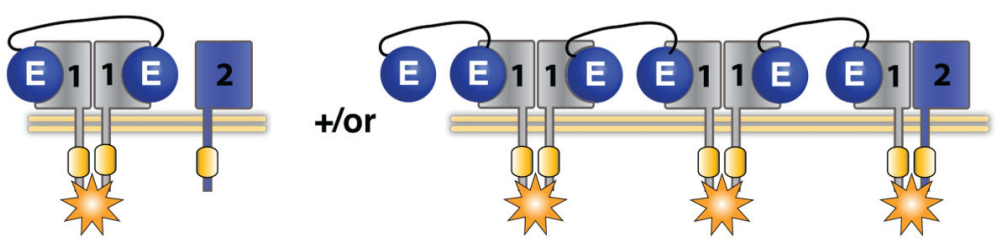

biased signaling

Figure 1.

Illustration of biased signaling in ErbB receptors with bivalent ligands $(\mathrm{E}=$ epidermal growth factor). 

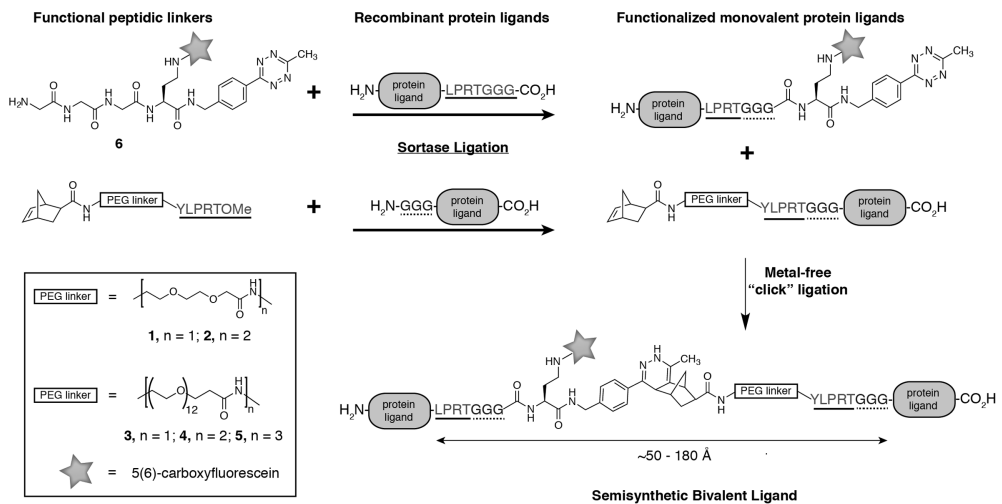

Figure 2.

Semisynthetic bivalent linkage strategy assembles two protein ligands with tunable functionality. Protein ligand, e.g. = Epidermal Growth Factor (EGF), Neuregulin (NRG). 

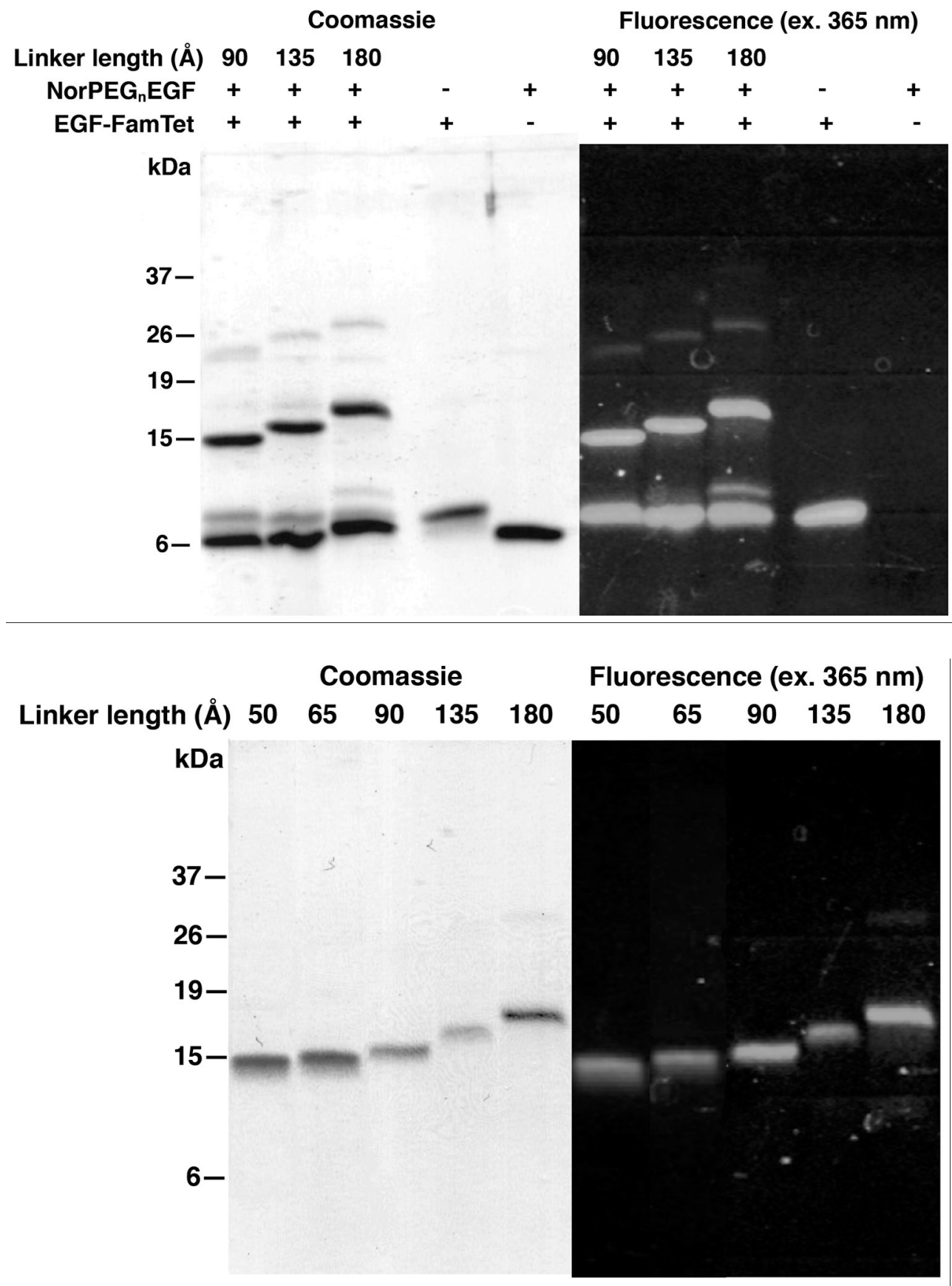

Figure 3.

Representative SDS-PAGE analyses A) click ligation reaction progress and B) final purified bivalent ligand set (bivalent EGFs (EEs) shown, for bivalent NRG (NN) see SI). 


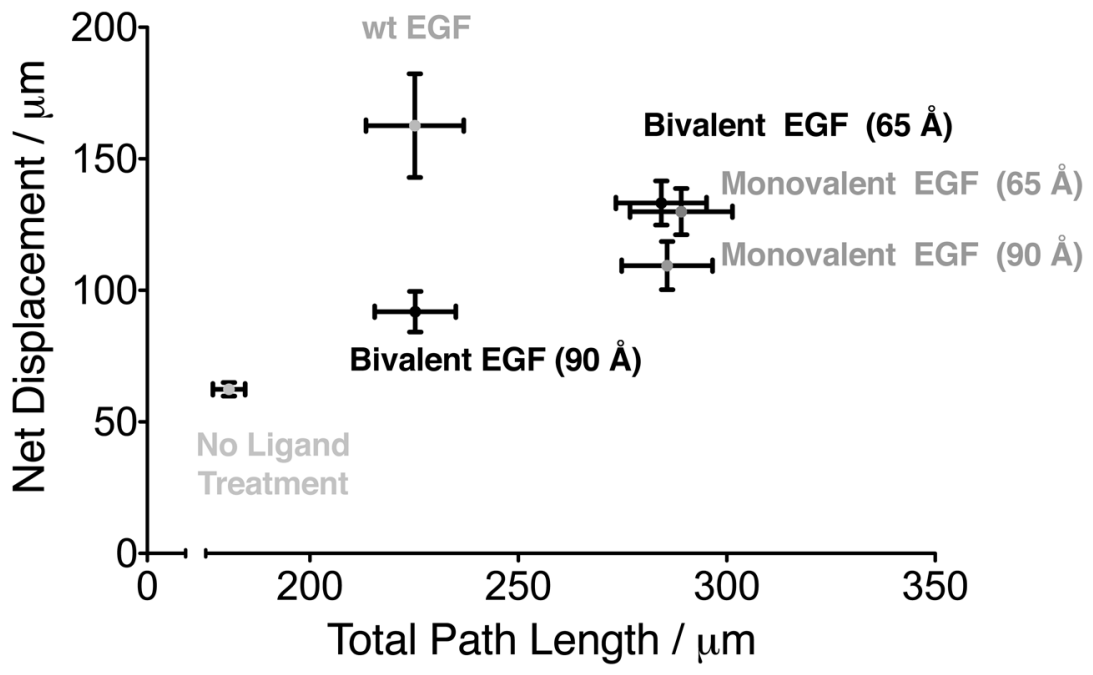

Wonovalent NorPEG-EGF

Bivalent EGF

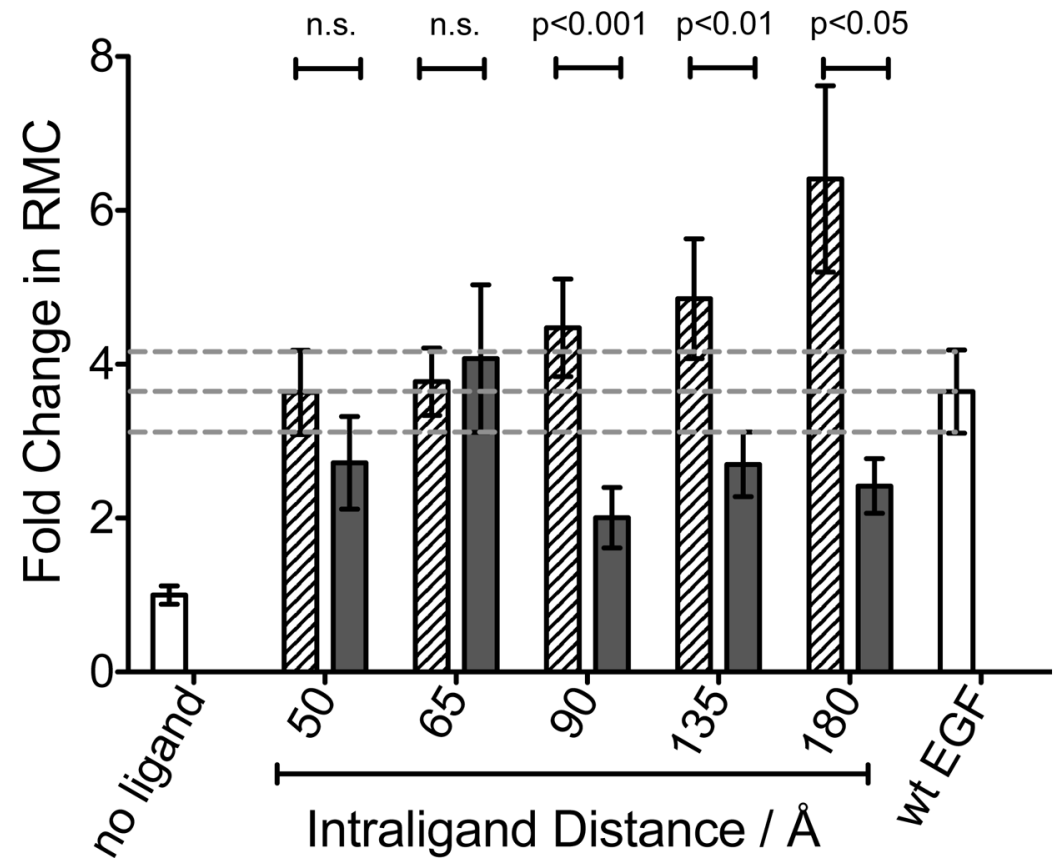

Figure 4.

hTMSC migration response to $100 \mathrm{nM}$ semisynthetic bivalent EGF ligand treatment as compared to the respective $\mathrm{PEG}_{\mathrm{n}}$-modified monovalent EGF. A) Mean and S.E. of the net displacement $(\mu \mathrm{m})$ and total path length $(\mu \mathrm{m})$ of hTMSCs upon treatment with monovalent and bivalent EGFs (65 ^ and $90 \AA$ ); B) Fold-change in the random motility coefficient (RMC) $\left(\mu \mathrm{m}^{2} / \mathrm{h}\right)$ in response to various ligand treatments. See SI for statistical analyses. 

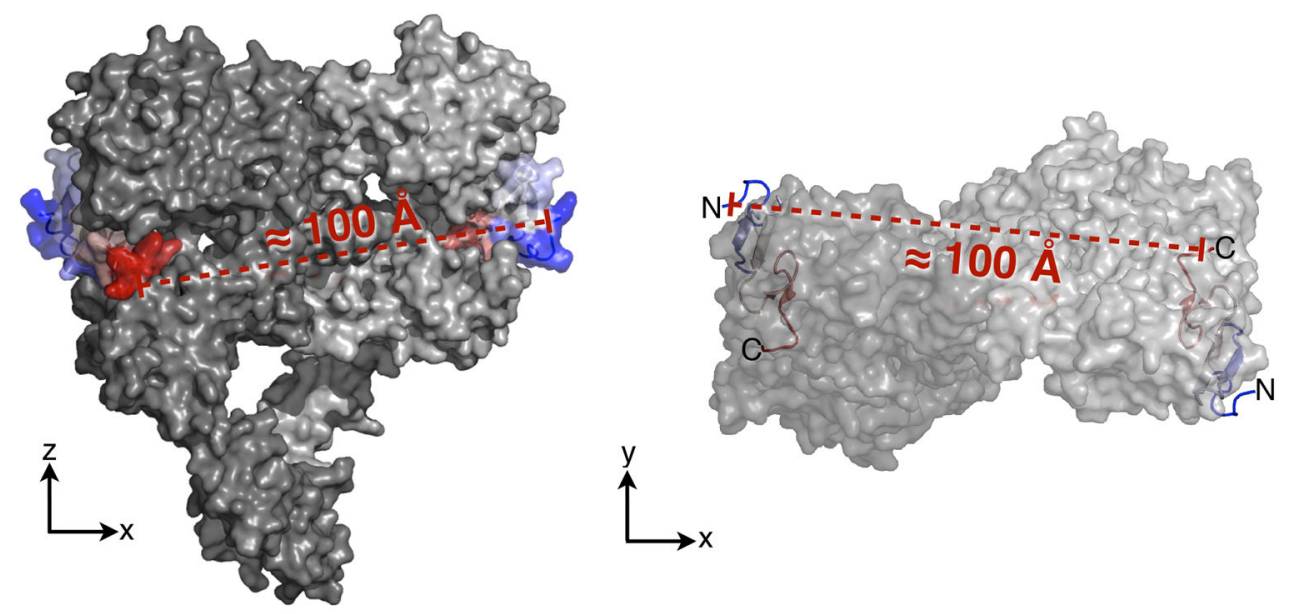

Figure 5.

Frontal (left) and top (right) views of crystal structure representation of a homodimer of two extracellular EGFR domains with two bound EGFs, indicating approximate distance between $\mathrm{C}, \mathrm{N}$ termini of EGF ligands. (PDB ID: 3NJP). ${ }^{13}$ 